\title{
BMJ Open Association between maternal education and malocclusion in Mongolian adolescents: a cross-sectional study
}

\author{
Tsasan Tumurkhuu, ${ }^{1}$ Takeo Fujiwara, ${ }^{2,3}$ Yuko Komazaki, ${ }^{1}$ Yoko Kawaguchi, ${ }^{4}$ \\ Toshihiro Tanaka, ${ }^{5}$ Johji Inazawa, ${ }^{6}$ Ganjargal Ganburged, ${ }^{7}$ Amarsaikhan Bazar, ${ }^{8}$ \\ Takuya Ogawa, ${ }^{1}$ Keiji Moriyama ${ }^{1}$
}

To cite: Tumurkhuu T, Fujiwara T, Komazaki Y, et al. Association between maternal education and malocclusion in Mongolian adolescents: a cross-sectional study. BMJ Open 2016;6:e012283. doi:10.1136/bmjopen-2016012283

- Prepublication history and additional material is available. To view please visit the journal (http://dx.doi.org/ 10.1136/bmjopen-2016012283).

Received 13 April 2016 Revised 24 August 2016 Accepted 12 September 2016

CrossMark

For numbered affiliations see end of article.

Correspondence to Dr Takuya Ogawa; t-ogawa.mort@tmd.ac.jp

\section{ABSTRACT}

Objective: Malocclusion is a highly prevalent condition, affecting $20-60 \%$ of adolescents worldwide. Although its treatment is often expensive and unaffordable for disadvantaged individuals, few studies have examined the relationship between malocclusion and socioeconomic status. We investigated the prevalence of malocclusion among Mongolian adolescents and its association with maternal education in a community-based sample in Mongolia. Design: Cross-sectional study.

Settings: 2 large secondary schools with different backgrounds in Ulaanbaatar, Mongolia.

Participants: Complete dental casts of 557 randomly recruited Mongolian schoolchildren aged 11-16 years were evaluated using the Dental Health Component of the Index of Orthodontic Treatment Need to dichotomise orthodontic treatment requirements. Exclusion criteria were the presence of orthodontic treatment history and absence of maternal educational status. Questionnaires were administered to caregivers to assess socioeconomic status. Poisson regression analysis was performed to examine the association between malocclusion and maternal educational status.

Results: The prevalence of malocclusion requiring orthodontic treatment among all adolescents was $35.2 \%(95 \% \mathrm{Cl} 31.2$ to 39.2$)$. In the unadjusted analysis, the prevalence ratio (PR) for malocclusion was higher ( $P R=1.46 ; 95 \% \mathrm{Cl} 0.96$ to 2.20 ) among adolescents of mothers with a high educational background than among those of mothers with a low educational background. After adjusting for covariates, the PR remained significantly higher $(\mathrm{PR}=1.72 ; 95 \% \mathrm{Cl}$ 1.06 to 2.82) among adolescents of mothers with a high educational background. Other socioeconomic status variables, including family income and the educational level of the father, showed no association with malocclusion.

Conclusions: These findings suggest that malocclusion requiring orthodontic treatment in adolescents is more prevalent among children of mothers with high levels of education. Further studies are needed to clarify the behavioural factors and environmental circumstance that contribute to this.

\section{Strengths and limitations of this study}

- This study provides novel information about the prevalence and occlusal traits of malocclusion, as assessed by calibrated orthodontists among schoolchildren in the city of Ulaanbaatar.

- The use of multiple variables to describe the growth environment of the adolescents is a study strength.

- One limitation is that only two schools were studied, which could cause a sampling bias.

\section{INTRODUCTION}

Globally, malocclusion has been increasing with industrialisation in many populations, ${ }^{12}$ and has become so widespread that it is ranked as the third most prevalent oral health problem after dental caries and periodontal disease. ${ }^{3}$ Malocclusion, as defined by the Index of Orthodontic Treatment Need (IOTN) ${ }^{4}$ occurs in $20-60 \%$ of adolescents in Europe,${ }^{5}{ }^{6}$ in $20-50 \%$ in Asia, ${ }^{7-9}$ in $20-40 \%$ in Africa, ${ }^{10}{ }^{11}$ and in $20-30 \%$ in South America. ${ }^{12}$ Although it is not generally a lifethreatening condition, it is nevertheless a chronic state of dental deviation that can influence quality of life, particularly emotional and social well-being. ${ }^{13}$

Recent studies have emphasised the importance of environmental factors in the incidence of malocclusion. ${ }^{14-16}$ Malocclusion occurs during the developmental period, and represents a deviation from normal growth and development. Although it is affected to some extent by genetic variation, various environmental risk factors have previously been reported. ${ }^{16}{ }^{17}$ These include socioeconomic status and behavioural factors. Socioeconomic status is assessed by variables such as income, educational level and occupation, which fundamentally structure the condition or environmental circumstance. ${ }^{18}$ 
Behavioural risk factors are considered to be behaviours learnt through environmental circumstances. ${ }^{19}$

Behavioural risk factors are known to differ systematically between individuals of different socioeconomic status. ${ }^{18}$ Social inequalities in oral health have gained increasing attention in recent years, and the International Association for Dental Research's Global Oral Health Inequalities Research Agenda is accumulating evidence on oral health inequalities. ${ }^{20}$ Socioeconomic status determines social and material circumstances, individual psychological and behavioural factors, accessibility to health services, and even biological predispositions and processes. ${ }^{21}$ Treating malocclusion is often expensive and may be unaffordable for disadvantaged populations. The existence of social inequalities may therefore also affect malocclusion. However, there have been relatively few studies on malocclusion and socioeconomic status, and such studies are mainly from Europe and Brazil. ${ }^{22-24}$

Since 1990, the socioeconomic environment has changed drastically in Mongolia. This has altered the nature of male and female participation in the economy and destabilised their role in the family, resulting in an expanded role for women as a caregiver and household wage earner. ${ }^{25}$ The country's economic transition has also affected the traditional lifestyle, eating habits, living environment and health system, raising new health-related issues. ${ }^{26-28}$ One of the emerging issues is the high prevalence of dental caries among children, especially in urban areas; interestingly, children from Mongolian families with a higher socioeconomic status have been reported to have a higher prevalence of early childhood caries. ${ }^{29}$ Unless treated, this leads to early loss of primary teeth, which is associated with malocclusion. ${ }^{16}$ It is therefore possible that higher socioeconomic status might be associated with malocclusion.

Until now, no studies have investigated socioeconomic status and its association with malocclusion in East Asian populations, including Mongolia, despite the occurrence of major socioeconomic changes in these nations over recent decades. We therefore investigated the prevalence of malocclusion among Mongolian adolescents, and its association with maternal educational status in a community-based sample in Mongolia.

\section{MATERIALS AND METHODS}

\section{Design and settings}

This cross-sectional study, derived from the longitudinal population-based survey 'Craniofacial Collaborative Research,' was conducted by a team at Tokyo Medical and Dental University and the Mongolian National University of Medical Sciences. This article is structured according to STROBE guidelines for cross-sectional studies.

\section{Sampling and recruitment}

The study sample size was calculated based on previous studies of malocclusion in Europe $^{45}$ and Asia. ${ }^{8} 9$
Approximately $30 \%$ of schoolchildren were considered likely to have malocclusion requiring orthodontic treatment. We assumed that high and low maternal education levels would be found in a proportion ${ }^{30}$ of 1:2. With a test power of $80 \%$, a level of significance of $5 \%$ and differences in prevalence of $15 \%$, these assumptions yielded a sample size of 362 .

Ulaanbaatar, the capital city of Mongolia, was chosen as a convenient location for the study because almost half of the country's total population lives there (45.8\%), and more than one-third of the schoolchildren study there ( $\mathrm{N}=186822,37.7 \%)$. Ulaanbaatar has nine large districts, and the two largest, Bayanzürkh and Songino Khairkhan, were chosen for investigation. Two schools, the biggest in each district, with different backgrounds were selected. One school was located in Bayanzürkh, the largest of the nine districts, and the other in Songino Khairkhan, the second largest district, in a suburb of Ulaanbaatar. Each grade at these schools includes 2-14 classes. This broad variation in class number is related to a major school system transition in 2004-2008, which resulted in an uneven distribution of students enrolled in grades 6 and 7 . At each school, two classes were randomly selected from each of the 1st to 10 th grades (children aged 5-16 years); all students in the selected classes were contacted $(n=1540)$ (figure 1). Sealed packages including an invitation letter, an informed consent form and a study questionnaire were distributed by teachers to the participants. Written consent was obtained from 1347 schoolchildren (response rate $87.5 \%$ ). Data collection took place between September and October of 2013. We restricted the sample to schoolchildren aged 11 years or over, to evaluate malocclusion in late mixed and permanent dentition $(n=585)$, because studies have shown that the IOTN gives acceptable reproducibility after age 11-12 years. ${ }^{4}{ }^{31}$ We also excluded adolescents with a history of orthodontic treatment $(n=7)$. After excluding questionnaires that did not specify maternal educational status, the final sample consisted of 557 participants. We examined each participant using dental cast models, dental examination records with orthopantomographs and questionnaires completed by parents.

\section{Measurement of malocclusion}

Three orthodontists with at least 2 years of orthodontic training at the Department of Maxillofacial Orthognathics, Tokyo Medical and Dental University used the Dental Health Component of the IOTN ${ }^{4}$ to assess orthodontic treatment need based on dental calliper measurements (Matsui Measure Mfg. Co., Osaka, Japan) of participants' dental casts. There was substantial inter-rater agreement for IOTN diagnosis measured on 56 study models $(\kappa=0.68,96.7 \%$ agreement $)$. The reliability by type of malocclusion varied from slight to perfect agreement $(\kappa=0.14-1.00,91.1-100.0 \%$ agreement) (see online supplementary file). Impeded eruption had the lowest reliability $(\kappa=0.14,91.1 \%$ 
Figure 1 Flow chart of the sample selection process. IOTN, Index of Orthodontic Treatment Need.

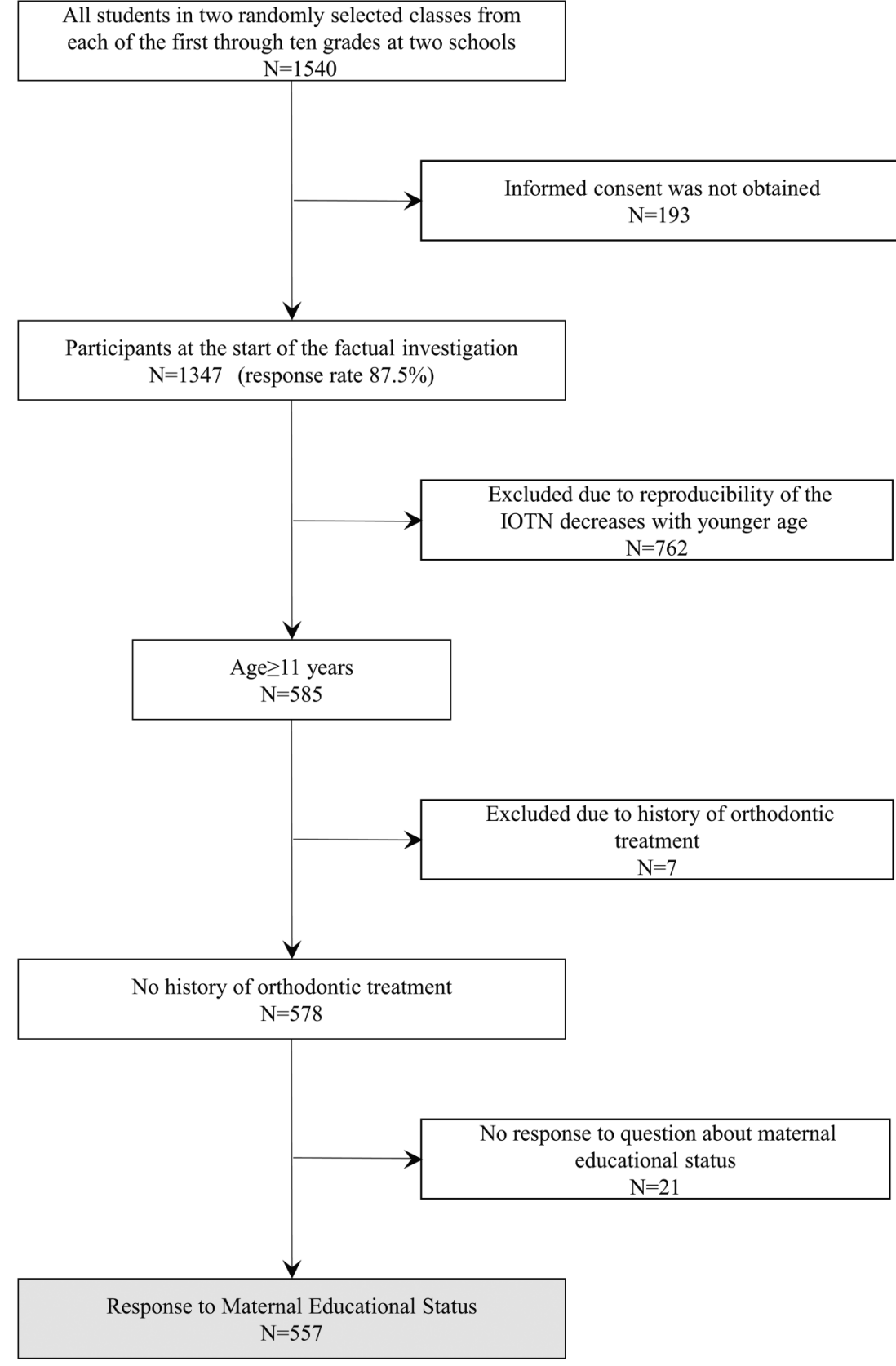

agreement), because our study sample consisted of adolescents with mixed and permanent dentition. We therefore re-evaluated each case with the help of orthopantomographic images to differentiate hypodontia from impeded tooth eruption. We chose to use orthopantomographs because impeded tooth eruption, defined as a missing tooth with $<4 \mathrm{~mm}$ of space because of tipping of adjacent teeth and visible buccal or lingual bulging of the alveolar bone, can sometimes be difficult to detect on maxillary dental casts, and because we had access to suitable radiographic images. Permanent first molar teeth missing on study models and orthopantomographic images were counted as extracted. ${ }^{4}$ Each model was given an IOTN grade; grades 4 and 5 were counted as 'needs treatment', and grades 1-3 were counted as 'no treatment needed'. 32 Dental age was estimated based on Hellman's ${ }^{33}$ dental age.

\section{Measurement of socioeconomic status}

We used questionnaire responses about parental educational background and household income as indicators of socioeconomic status. We used the following questions, answered by caregivers, to assess education: 'what kind of educational background does the mother have?' and 'what kind of educational background does the father have?'. Five response options were offered: 'no education was obtained', 'obtained compulsory primary or/and lower secondary education', 'completed high school', 'completed vocational school' and 'completed a bachelor's, master's or doctorate program'. The five 
response options were divided into three categories for statistical analysis. The first two options were categorised as 'low level of education', the second two as 'intermediate level of education' and the last as 'high level of education'.

\section{Covariates}

The following covariates, considered likely to be related to maternal educational status and malocclusion, were obtained through the questionnaire: participant's sex, birthdate (ie, age of participant), birth weight, fingersucking habit in childhood, frequency of tooth brushing, regular breakfast consumption, parents' age, mother's lifestyle during pregnancy (drinking and smoking habits, X-ray exposure), early childhood care (type of feeding and use of a pacifier), and environmental conditions in which the participant grew up (number of children in the family, type of dwelling). Birth weight was obtained as a quantitative variable and was categorised into two groups $(\geq 2500$ or $<2500 \mathrm{~g}$ ), because low birth weight has been reported as a risk factor for malocclusion. ${ }^{34}$ Maternal lifestyle during pregnancy was considered on the basis of life course perspective about the development of oral disease. ${ }^{35}$ Maternal drinking, smoking habits and X-ray exposure during pregnancy were dichotomised as 'yes' or 'no' during statistical analysis. Level of dental caries was obtained during dental check-ups, to use as a potential confounder during statistical analysis. It was initially recorded to provide parents with feedback about participants' oral health status. Four resident doctors in the Department of Pediatric and Preventive Dentistry, School of Dentistry, Mongolian National University of Medical Sciences examined participants using dental mirrors and orthopantomographic $\mathrm{X}$-ray images. They checked that their diagnoses matched during examination of the initial class. The total number of decayed and filled teeth was counted to provide a measure of experience of dental caries.

\section{Data analysis}

Demographic variables of participants with malocclusion requiring orthodontic treatment were compared with those of participants not needing treatment, using $\chi^{2}$ and Student's t-test analysis. Analysis of variance (ANOVA) was used for quantitative variables of dental status to observe their distribution. Data on maternal age were missing for 14 participants and the average maternal age was therefore used for statistical analysis in these cases. The same method was used for number of children in the family, which was missing for two participants. One participant's dental record was not obtained; the average experience of dental caries was used in this case for statistical analysis. The association between maternal education and malocclusion was compared using Poisson regression analysis, because of the relatively high prevalence of malocclusion. ${ }^{36}$ Paternal educational status and income and gestational age at birth were excluded from the Poisson analysis because of multicollinearity. Model 1 adjusted for maternal age, education level, and lifestyle (drinking and smoking habits and X-ray exposure) during pregnancy, and participant's sex and age. Model 2 adjusted for maternal age and education level, participant's sex and age, birth weight, environmental conditions (number of children in the family and type of dwelling), type of feeding and pacifier use, finger-sucking habit during childhood, frequency of tooth brushing, level of dental caries and regular breakfast consumption. Model 3 adjusted for maternal age, education level, and lifestyle during pregnancy, participant's sex and age, birth weight, environmental conditions (number of children in the family and type of dwelling), type of feeding and pacifier use, fingersucking habit during childhood, frequency of tooth brushing, level of dental caries and regular breakfast consumption. The significance level was set at $\mathrm{p}<0.05$. Stata V.12 SE (StataCorp LP, College Station, Texas, USA) was used for all statistical analyses.

\section{RESULTS}

The prevalence of malocclusion requiring orthodontic treatment among all the adolescents was $35.2 \%$ (95\% CI $31.2 \%$ to $39.2 \%$ ). The prevalence of malocclusion was higher in men (38.4\%; $95 \%$ CI $32.3 \%$ to $44.5 \%$ ) than in women $(32.6 \%$; $95 \%$ CI $27.3 \%$ to $37.8 \%)$, but this difference was not statistically significant (table 1).

Table 2 shows the distribution of characteristics of participants, dichotomised by the presence of malocclusion. Overall, the mothers of $209(37.5 \%)$ adolescents had high levels of education, $243(43.6 \%)$ had intermediate levels and 105 (18.9\%) had low levels. Higher levels of maternal education were associated with an increase in the prevalence of malocclusion in the participants. The $\chi^{2}$ test revealed no significant association between malocclusion and duration of using a pacifier, finger-sucking habit or bottle feeding (data not shown).

Table 1 Distribution of malocclusion requiring orthodontic treatment, according to gender

\begin{tabular}{|c|c|c|c|c|c|c|c|}
\hline & \multicolumn{2}{|c|}{$\begin{array}{l}\text { All } \\
(n=557,100 \%)\end{array}$} & \multicolumn{2}{|c|}{$\begin{array}{l}\text { Male } \\
(n=250,45 \%)\end{array}$} & \multicolumn{2}{|c|}{$\begin{array}{l}\text { Female } \\
(n=307,55 \%)\end{array}$} & \multirow[b]{2}{*}{$p$ for $\chi^{2}$ tes } \\
\hline & $\mathbf{N}$ & Per cent & $\mathbf{N}$ & Per cent & $\mathbf{N}$ & Per cent & \\
\hline Malocclusion (+) & 196 & 35 & 96 & 38 & 100 & 33 & 0.15 \\
\hline Malocclusion (-) & 361 & 65 & 154 & 62 & 207 & 67 & \\
\hline
\end{tabular}


Table 2 Characteristics of participants, by presence of malocclusion

\begin{tabular}{|c|c|c|c|c|c|c|c|}
\hline & \multicolumn{2}{|c|}{ All $(n=557,100 \%)$} & \multicolumn{2}{|c|}{$\begin{array}{l}\text { Malocclusion (-) } \\
(\mathrm{n}=361,65 \%)\end{array}$} & \multicolumn{2}{|c|}{$\begin{array}{l}\text { Malocclusion }(+) \\
(n=196,35 \%)\end{array}$} & \multirow[b]{2}{*}{$\begin{array}{l}p \text { for } \chi^{2} \\
\text { test }\end{array}$} \\
\hline & $\begin{array}{l}\mathrm{N} \text { or } \\
\text { mean }\end{array}$ & $\begin{array}{l}\text { Per cent or } \\
\text { SD }\end{array}$ & $\begin{array}{l}\mathrm{N} \text { or } \\
\text { mean }\end{array}$ & $\begin{array}{l}\text { Per cent or } \\
\text { SD }\end{array}$ & $\begin{array}{l}\mathrm{N} \text { or } \\
\text { mean }\end{array}$ & $\begin{array}{l}\text { Per cent or } \\
\text { SD }\end{array}$ & \\
\hline Age of fathert & 40.3 & 5.8 & 40.6 & 5.8 & 39.7 & 5.6 & 0.13 \\
\hline Age of mother $\dagger$ & 38.6 & 5.5 & 38.8 & 5.7 & 38.3 & 5.1 & 0.31 \\
\hline \multicolumn{8}{|l|}{ Education level of father } \\
\hline High & 139 & 25 & 86 & 24 & 53 & 27 & 0.69 \\
\hline Intermediate & 254 & 46 & 163 & 45 & 91 & 46 & \\
\hline Low & 113 & 20 & 77 & 21 & 36 & 18 & \\
\hline \multicolumn{8}{|l|}{ Education level of mother } \\
\hline High & 209 & 38 & 122 & 34 & 87 & 44 & $0.037^{*}$ \\
\hline Intermediate & 243 & 44 & 164 & 45 & 79 & 40 & \\
\hline Low & 105 & 19 & 75 & 21 & 30 & 15 & \\
\hline \multicolumn{8}{|l|}{ Family income level } \\
\hline High & 97 & 17 & 61 & 17 & 36 & 18 & 0.86 \\
\hline Intermediate & 289 & 52 & 189 & 52 & 100 & 51 & \\
\hline Low & 160 & 29 & 105 & 29 & 55 & 28 & \\
\hline $\begin{array}{l}\text { Number of children in the } \\
\text { familyt }\end{array}$ & 2.6 & 1.1 & 2.6 & 1.0 & 2.6 & 1.1 & 0.62 \\
\hline \multicolumn{8}{|l|}{ Dwelling } \\
\hline Traditional 'ger' & 133 & 24 & 92 & 26 & 41 & 21 & 0.56 \\
\hline Detached house & 219 & 39 & 139 & 39 & 80 & 41 & \\
\hline Apartment complex & 204 & 37 & 129 & 36 & 75 & 38 & \\
\hline \multicolumn{8}{|l|}{ School location } \\
\hline $\begin{array}{l}\text { Outside of the centre of the } \\
\text { city }\end{array}$ & 263 & 47 & 177 & 49 & 86 & 44 & 0.25 \\
\hline At the centre of the city & 294 & 53 & 184 & 51 & 110 & 56 & \\
\hline \multicolumn{8}{|c|}{ Drinking habit of mother during pregnancy } \\
\hline$(+)$ & 18 & 3 & 12 & 3 & 6 & 3 & 0.99 \\
\hline$(-)$ & 496 & 89 & 321 & 89 & 175 & 89 & \\
\hline \multicolumn{8}{|l|}{ Smoking habit of mother } \\
\hline$(+)$ & 16 & 3 & 9 & 3 & 7 & 4 & 0.30 \\
\hline$(-)$ & 540 & 97 & 352 & 98 & 188 & 96 & \\
\hline \multicolumn{8}{|c|}{ X-ray exposure during pregnancy } \\
\hline$(+)$ & 102 & 18 & 70 & 19 & 32 & 16 & 0.23 \\
\hline$(-)$ & 366 & 66 & 240 & 67 & 126 & 64 & \\
\hline Age of participant $†$ & 12.8 & 1.3 & 12.8 & 1.3 & 12.9 & 1.3 & 0.20 \\
\hline \multicolumn{8}{|l|}{ Birth weight } \\
\hline$<2500 \mathrm{~g}$ & 19 & 3 & 16 & 4 & 3 & 2 & 0.15 \\
\hline$\geq 2500 \mathrm{~g}$ & 473 & 85 & 306 & 85 & 167 & 85 & \\
\hline \multicolumn{8}{|l|}{ Gestational age at birth } \\
\hline$<37$ weeks of pregnancy & 28 & 5 & 21 & 6 & 7 & 4 & 0.18 \\
\hline$\geq 37$ weeks of pregnancy & 507 & 91 & 329 & 91 & 178 & 91 & \\
\hline \multicolumn{8}{|c|}{ Type of feeding in early childhood } \\
\hline Breast feeding only & 385 & 69 & 253 & 70 & 132 & 67 & $0.018^{*}$ \\
\hline Mixed feeding & 133 & 24 & 88 & 24 & 45 & 23 & \\
\hline Bottle feeding only & 31 & 6 & 19 & 5 & 12 & 6 & \\
\hline \multicolumn{8}{|c|}{ Use of a pacifier during childhood } \\
\hline$(+)$ & 99 & 18 & 60 & 17 & 39 & 20 & 0.11 \\
\hline$(-)$ & 442 & 79 & 294 & 81 & 148 & 76 & \\
\hline \multicolumn{8}{|c|}{ Finger-sucking habit during childhood } \\
\hline$(+)$ & 36 & 7 & 21 & 6 & 15 & 8 & 0.43 \\
\hline$(-)$ & 506 & 91 & 332 & 92 & 174 & 89 & \\
\hline \multicolumn{8}{|l|}{ Frequency of tooth brushing } \\
\hline More than once a day & 233 & 42 & 159 & 44 & 74 & 38 & 0.35 \\
\hline Once a day & 257 & 46 & 160 & 44 & 97 & 50 & \\
\hline Not every day & 62 & 11 & 40 & 11 & 22 & 11 & \\
\hline
\end{tabular}


Table 2 Continued

\begin{tabular}{|c|c|c|c|c|c|c|c|}
\hline & \multicolumn{2}{|c|}{ All $(n=557,100 \%)$} & \multicolumn{2}{|c|}{$\begin{array}{l}\text { Malocclusion }(-) \\
(n=361,65 \%)\end{array}$} & \multicolumn{2}{|c|}{$\begin{array}{l}\text { Malocclusion }(+) \\
(n=196,35 \%)\end{array}$} & \multirow[b]{2}{*}{$\begin{array}{l}p \text { for } \chi^{2} \\
\text { test }\end{array}$} \\
\hline & $\begin{array}{l}\mathrm{N} \text { or } \\
\text { mean }\end{array}$ & $\begin{array}{l}\text { Per cent or } \\
\text { SD }\end{array}$ & $\begin{array}{l}\mathrm{N} \text { or } \\
\text { mean }\end{array}$ & $\begin{array}{l}\text { Per cent or } \\
\text { SD }\end{array}$ & $\begin{array}{l}\mathrm{N} \text { or } \\
\text { mean }\end{array}$ & $\begin{array}{l}\text { Per cent or } \\
\text { SD }\end{array}$ & \\
\hline \multicolumn{8}{|c|}{ Regular breakfast } \\
\hline$(+)$ & 333 & 60 & 217 & 60 & 116 & 59 & 0.83 \\
\hline$(-)$ & 224 & 40 & 144 & 40 & 80 & 41 & \\
\hline
\end{tabular}

${ }^{*} \mathrm{p}<0.05$.

†Continuous variables were analysed using Student's t-test.

Table 3 shows the occlusal characteristics of the malocclusions and dental status stratified by maternal education level. Of the occlusal traits used for diagnosing malocclusion, distribution of the molar relationship assessed by Angle classification, where the molar occlusion deviates by more than half a buccal unit, was statistically significant. Impeded eruption of teeth showed a tendency towards a positive relationship with maternal education level, but this was not statistically significant.

Table 4 shows the prevalence ratio (PR) for malocclusion by maternal educational status. Adolescents whose mothers had intermediate or advanced education had a higher PR for malocclusion needing orthodontic treatment than those with lower levels of education $(\mathrm{PR}=1.13 ; 95 \%$ CI 0.75 to 1.73 and $\mathrm{PR}=1.46 ; 95 \%$ CI 0.96 to 2.20 ). This association remained significant even after adjustment for covariates, testing maternal variables during pregnancy in model 1 and all covariates in model 3. In model 2, testing participants' variables, the association remained consistent but was not significant.

\section{DISCUSSION}

To the best of our knowledge, this is the first study examining the association between maternal education and malocclusion among adolescents in Mongolia, a developing country where economic growth has rapidly increased. Many of those who were young people during the period of rapid socioeconomic transition have now become parents. We consider that this is therefore an optimal model to show how socioeconomic change influences the oral health of the next generation. Our results show an independent association between higher maternal educational status and malocclusion in children. A possible interpretation for this result of malocclusion as an oral health outcome is that when socioeconomic transition occurs in developing countries or in regions with clear socioeconomic disparity, women with higher levels of education or socioeconomic status change their lifestyle faster, resulting in poorer oral health. ${ }^{29} 3738$ A fluctuating national socioeconomic position does not always guarantee healthy food, healthy eating behaviours, good provision of information about the potential health risks of new lifestyles or suitable countermeasures, or a healthy living environment. The reverse gradient has been observed for a number of health outcomes, such as breast cancer, malignant melanoma, obesity and lung cancer. Behaviours that differ by socioeconomic status play a role in the mechanisms of these health outcomes, and when public health intervention is applied to such behaviours, this reverse gradient changes. ${ }^{21} 39$

In this study, we considered models assessing maternal factors (model 1) and participants' factors (model 2). The association between maternal education and malocclusion was slightly weaker for the participants' factors. In model 1 , behaviours related to maternal educational level were included to test for causal links, because maternal behavioural variables are closely associated with maternal education level. In model 2, birth weight, type of feeding during early childhood, type of dwelling and school location were considered as mediators related to socioeconomic status. Mediators related to participants' behavioural factors were non-nutritive sucking habits such as use of a pacifier during childhood, finger-sucking habit, ${ }^{16}$ frequency of tooth brushing and regular breakfast habits. Low birth weight has been reported as a risk factor for malocclusion ${ }^{34}$ and also to be associated with low levels of maternal education in Mongolia, particularly no education. ${ }^{40}$ However, in our sample, low birth weight was associated with women with high levels of education, showing the possibility of response bias. Sucking habits including a pacifier, a feeding bottle and a finger have previously been reported as risk factors for malocclusion, even if they occurred only for a short time. This suggests that they could directly influence the developing occlusion and indirectly change swallowing patterns. ${ }^{15}$ Behaviours such as regular consumption of breakfast and tooth brushing habits were considered to be indices of the health education level of participants, but did not show any strong associations. It may be that other behavioural factors or the presence of chronic upper respiratory disease could explain the association between maternal education and children's malocclusion, but we did not investigate these. It is known that there are inequalities in the distribution of highly educated women between urban and rural areas, with women with high levels of education concentrated in Ulaanbaatar. ${ }^{30} \mathrm{~A}$ previous study reported that chronic upper respiratory disease has increased in urban areas, and that there are different 
Table 3 Distribution of occlusal traits and malocclusion requiring treatment by education level of mother

\begin{tabular}{|c|c|c|c|c|c|c|c|c|c|}
\hline & \multicolumn{2}{|c|}{$\begin{array}{l}\text { All }(n=557 \\
100 \%)\end{array}$} & \multicolumn{6}{|c|}{ Education level of mother } & \multirow[b]{3}{*}{$\begin{array}{l}p \text { for } \chi^{2} \\
\text { test }\end{array}$} \\
\hline & \multirow[b]{2}{*}{$\begin{array}{l}\mathrm{N} \text { or } \\
\text { mean }\end{array}$} & \multirow{2}{*}{$\begin{array}{l}\text { Per cent } \\
\text { or SD }\end{array}$} & \multicolumn{2}{|c|}{$\begin{array}{l}\text { Low } \\
(n=105,19 \%)\end{array}$} & \multicolumn{2}{|c|}{$\begin{array}{l}\text { Intermediate } \\
(n=243,44 \%)\end{array}$} & \multicolumn{2}{|c|}{$\begin{array}{l}\text { High } \\
(n=209,38 \%)\end{array}$} & \\
\hline & & & $\begin{array}{l}\mathrm{N} \text { or } \\
\text { mean }\end{array}$ & $\begin{array}{l}\text { Per cent } \\
\text { or SD }\end{array}$ & $\begin{array}{l}\mathrm{N} \text { or } \\
\text { mean }\end{array}$ & $\begin{array}{l}\text { Per cent } \\
\text { or SD }\end{array}$ & $\begin{array}{l}\mathrm{N} \text { or } \\
\text { mean }\end{array}$ & $\begin{array}{l}\text { Per cent } \\
\text { or SD }\end{array}$ & \\
\hline \multicolumn{10}{|l|}{ Occlusal traits not used for diagnosis } \\
\hline \multicolumn{10}{|l|}{ Dental age } \\
\hline III B & 99 & 18 & 16 & 15 & 42 & 17 & 41 & 20 & 0.15 \\
\hline III C & 290 & 52 & 66 & 63 & 122 & 50 & 102 & 49 & \\
\hline IV A & 168 & 30 & 23 & 22 & 79 & 33 & 66 & 32 & \\
\hline Midline discrepancy $(\mathrm{mm}) \dagger$ & 0.8 & 1.0 & 0.8 & 1.0 & 0.8 & 0.8 & 0.9 & 1.1 & 0.17 \\
\hline Tooth size of upper left incisor $(\mathrm{mm}) \dagger$ & 8.7 & 0.7 & 8.7 & 0.5 & 8.6 & 0.9 & 8.8 & 0.5 & 0.07 \\
\hline $\begin{array}{l}\text { Level of dental caries (sum of } \\
\text { decayed, filled teeth for mixed and } \\
\text { permanent dentition)† }\end{array}$ & 5.6 & 3.5 & 5.5 & 3.3 & 5.9 & 3.6 & 5.4 & 3.3 & 0.29 \\
\hline \multicolumn{6}{|l|}{ Occlusal traits used for diagnosis } & & & & \\
\hline$>6 \mathrm{~mm}$ & 20 & 4 & 4 & 4 & 9 & 4 & 7 & 3 & 0.97 \\
\hline$\leq 6 \mathrm{~mm}$ & 537 & 96 & 101 & 96 & 234 & 96 & 202 & 97 & \\
\hline \multicolumn{10}{|c|}{ Reverse overjet which needs treatment } \\
\hline$>1 \mathrm{~mm}$ & 12 & 2 & 1 & 1 & 5 & 2 & 6 & 3 & 0.54 \\
\hline$\leq 1 \mathrm{~mm}$ & 545 & 98 & 104 & 99 & 238 & 98 & 203 & 97 & \\
\hline \multicolumn{10}{|l|}{ Deep bite } \\
\hline $\begin{array}{l}\text { Deep bite causing notable } \\
\text { indentations of the palatal gingivae }\end{array}$ & 5 & 1 & 1 & 1 & 0 & 0 & 4 & 2 & 0.10 \\
\hline $\begin{array}{l}\text { Deep bite or normal overbite without } \\
\text { indentations or signs of trauma }\end{array}$ & 552 & 99 & 104 & 99 & 243 & 100 & 205 & 98 & \\
\hline \multicolumn{10}{|l|}{ Open bite which needs treatment } \\
\hline$>4 \mathrm{~mm}$ & 1 & 0 & 0 & 0 & 0 & 0 & 1 & 1 & 0.43 \\
\hline$\leq 4 \mathrm{~mm}$ & 556 & 100 & 105 & 100 & 243 & 100 & 208 & 100 & \\
\hline \multicolumn{10}{|l|}{ Anterior crossbite } \\
\hline$(+)$ & 60 & 11 & 9 & 9 & 24 & 10 & 27 & 13 & 0.42 \\
\hline$(-)$ & 497 & 89 & 96 & 91 & 219 & 90 & 182 & 87 & \\
\hline \multicolumn{10}{|l|}{ Posterior crossbite } \\
\hline$(+)$ & 48 & 9 & 8 & 8 & 21 & 9 & 19 & 9 & 0.91 \\
\hline$(-)$ & 509 & 91 & 97 & 92 & 222 & 91 & 190 & 91 & \\
\hline \multicolumn{10}{|l|}{ Scissor bite } \\
\hline$(+)$ & 30 & 5 & 5 & 5 & 15 & 6 & 10 & 5 & 0.77 \\
\hline$(-)$ & 527 & 95 & 100 & 95 & 228 & 94 & 199 & 98 & \\
\hline \multicolumn{10}{|c|}{ Displacement of teeth in the maxillary arch which needs treatment } \\
\hline$>4 \mathrm{~mm}$ & 70 & 13 & 13 & 12 & 28 & 12 & 29 & 14 & 0.75 \\
\hline$\leq 4 \mathrm{~mm}$ & 487 & 87 & 92 & 88 & 215 & 89 & 180 & 86 & \\
\hline Displacement of teeth in the mandibula & arch $w$ & hich needs & treatme & & & & & & \\
\hline$>4 \mathrm{~mm}$ & 20 & 4 & 5 & 5 & 11 & 5 & 4 & 2 & 0.26 \\
\hline$\leq 4 \mathrm{~mm}$ & 537 & 96 & 100 & 95 & 232 & 96 & 205 & 98 & \\
\hline Cleft lip and/or palate & & & & & & & & & \\
\hline$(+)$ & 1 & 0 & 0 & 0 & 0 & 0 & 1 & 1 & 0.43 \\
\hline$(-)$ & 556 & 100 & 105 & 100 & 243 & 100 & 208 & 100 & \\
\hline Hypodontia which needs treatment & & & & & & & & & \\
\hline$(+)$ & 26 & 5 & 2 & 2 & 8 & 3 & 16 & 8 & $0.030^{*}$ \\
\hline$(-)$ & 531 & 95 & 103 & 98 & 235 & 97 & 193 & 92 & \\
\hline Impeded eruption & & & & & & & & & \\
\hline$(+)$ & 11 & 2 & 3 & 3 & 1 & 0 & 7 & 3 & 0.06 \\
\hline$(-)$ & 546 & 98 & 102 & 97 & 242 & 100 & 202 & 97 & \\
\hline Partially erupted teeth, tipped and impa & acted ag & inst adjace & nt teeth & & & & & & \\
\hline$(+)$ & 10 & 2 & 2 & 2 & 4 & 2 & 4 & 2 & 0.97 \\
\hline$(-)$ & 547 & 98 & 103 & 98 & 239 & 98 & 205 & 98 & \\
\hline
\end{tabular}


Table 3 Continued

\begin{tabular}{|c|c|c|c|c|c|c|c|c|c|}
\hline & \multicolumn{2}{|c|}{$\begin{array}{l}\text { All }(n=557, \\
100 \%)\end{array}$} & \multicolumn{6}{|c|}{ Education level of mother } & \multirow[b]{3}{*}{$\begin{array}{l}p \text { for } \chi^{2} \\
\text { test }\end{array}$} \\
\hline & \multirow[b]{2}{*}{$\begin{array}{l}\mathrm{N} \text { or } \\
\text { mean }\end{array}$} & \multirow{2}{*}{$\begin{array}{l}\text { Per cent } \\
\text { or SD }\end{array}$} & \multicolumn{2}{|c|}{$\begin{array}{l}\text { Low } \\
(n=105,19 \%)\end{array}$} & \multicolumn{2}{|c|}{$\begin{array}{l}\text { Intermediate } \\
(n=243,44 \%)\end{array}$} & \multicolumn{2}{|c|}{$\begin{array}{l}\text { High } \\
(n=209,38 \%)\end{array}$} & \\
\hline & & & $\begin{array}{l}\mathrm{N} \text { or } \\
\text { mean }\end{array}$ & $\begin{array}{l}\text { Per cent } \\
\text { or SD }\end{array}$ & $\begin{array}{l}\mathrm{N} \text { or } \\
\text { mean }\end{array}$ & $\begin{array}{l}\text { Per cent } \\
\text { or SD }\end{array}$ & $\begin{array}{l}\mathrm{N} \text { or } \\
\text { mean }\end{array}$ & $\begin{array}{l}\text { Per cent } \\
\text { or SD }\end{array}$ & \\
\hline \multicolumn{10}{|c|}{ Presence of supernumerary teeth } \\
\hline$(+)$ & 2 & 0 & 0 & 0 & 2 & 1 & 0 & 0 & 0.27 \\
\hline$(-)$ & 555 & 100 & 105 & 100 & 241 & 99 & 209 & 100 & \\
\hline \multicolumn{10}{|c|}{ Molar relationship by Angle Classification } \\
\hline Class I & 349 & 63 & 57 & 54 & 150 & 62 & 142 & 68 & $0.006^{*}$ \\
\hline Class II & 113 & 20 & 27 & 26 & 46 & 19 & 40 & 19 & \\
\hline Class III & 37 & 7 & 6 & 6 & 13 & 5 & 18 & 9 & \\
\hline Not applicable & 58 & 10 & 15 & 14 & 34 & 14 & 9 & 4 & \\
\hline \multicolumn{10}{|c|}{ Diagnosed malocclusion } \\
\hline Grade 1 & 39 & 7 & 7 & 7 & 20 & 8 & 12 & 6 & 0.13 \\
\hline Grade 2 & 110 & 20 & 24 & 23 & 50 & 21 & 36 & 17 & \\
\hline Grade 3 & 212 & 38 & 44 & 42 & 94 & 39 & 74 & 35 & \\
\hline Grade 4 & 181 & 33 & 27 & 26 & 77 & 32 & 77 & 37 & \\
\hline Grade 5 & 15 & 3 & 3 & 3 & 2 & 1 & 10 & 5 & \\
\hline \multicolumn{10}{|c|}{ Malocclusion requiring treatment } \\
\hline$(+)$ & 196 & 35 & 30 & 29 & 79 & 33 & 87 & 42 & $0.037^{*}$ \\
\hline$(-)$ & 361 & 65 & 75 & 71 & 164 & 68 & 122 & 58 & \\
\hline
\end{tabular}

risk levels among those living in rural areas from birth, those who have migrated from rural to urban areas and those living in Ulaanbaatar from birth. ${ }^{41}$ Further studies are needed to investigate these factors.

We used the participants' present level of dental caries as a covariate. However, the prevalence of dental caries in the studied population was very high $(95.1 \%)$ and there was no statistical difference in distribution by maternal educational status. We have no available data about the oral health condition and severity of dental caries in the deciduous dentition of our sample. In a study in 2004-2005, among children aged 1-5 years in Ulaanbaatar, children aged 3-5 years from families with higher socioeconomic status had a significantly higher incidence of dental caries. ${ }^{29}$ The children in that study are now adolescents, and their age matches the ages of our sample. It could be speculated that early childhood caries and its severity could have a possible causal relationship. Other studies have supported a reverse relationship between socioeconomic status and malocclusion, ${ }^{22} 42$ showing a higher incidence of dental caries in the deprived group and a greater likelihood of living in regions without fluoridated tap water. It is possible that inflammation from apical periodontitis, improper treatment or early loss of deciduous teeth during childhood may have caused migration of the dental follicle of permanent teeth, contributing to malocclusion. Interestingly, a few occlusal traits, such as distribution of the molar relationship assessed by Angle classification, and impeded eruption, appeared to support this relationship. However, to confirm this speculation, further longitudinal research following a cohort from early childhood to adolescence would be needed. This positive association between maternal education and malocclusion might be indicative of the oral health conditions in society at the present time. If an identical study is repeated in a few decades, after further changes to the national socioeconomic environment or significant decline in dental caries in the overall population, completely different results might be obtained.

Mongolia has unique dietary traditions, with a focus on meat and dairy products, ${ }^{27} 2843$ predominantly hard or densely textured foods, and little consumption of vegetables, rice or wheat. After the collapse of the socialist regime, free markets enabled access to a variety of imported products, mainly processed foods, because of their durability for transport and storage stability. Fresh vegetables and fruits are available during the summer but are expensive. Mothers with a low educational background tend to provide more traditional food and to purchase meat rather than vegetables. ${ }^{26}$ Our results could be interpreted as indicating that mothers with higher levels of education prepare softer or more processed foods, offer more variety in the diet and a less traditional diet, which decreases masticatory jaw function in their offspring. ${ }^{44}$ Children of mothers with a lower educational background, or who have less to spend and may live more self-sufficient lifestyles or in families of herdsmen, consume more traditional foods, ${ }^{27} 45$ maintaining an environment that optimises 
Table 4 Prevalence ratio (PR) of malocclusion requiring orthodontic treatment by maternal education level

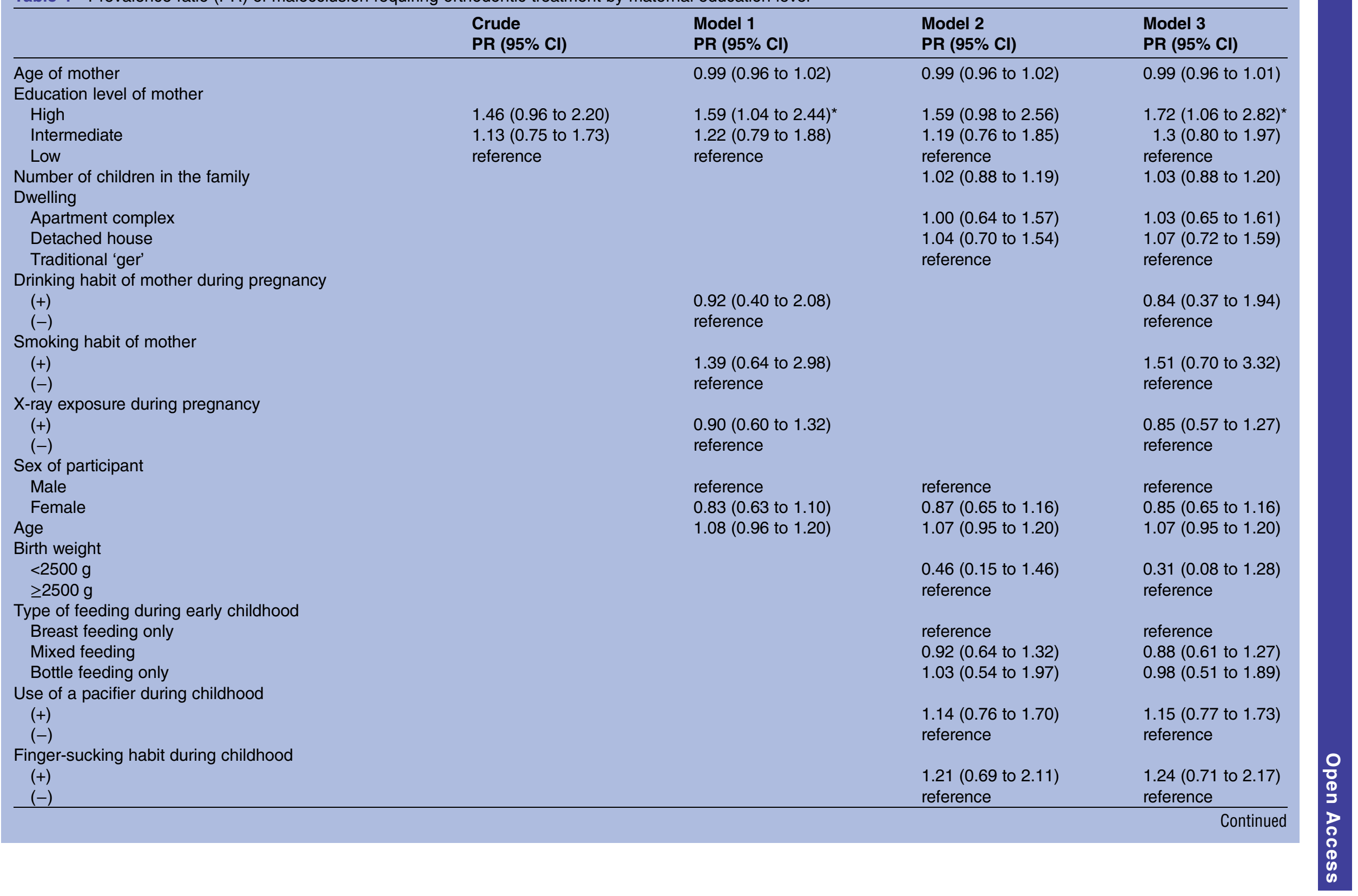




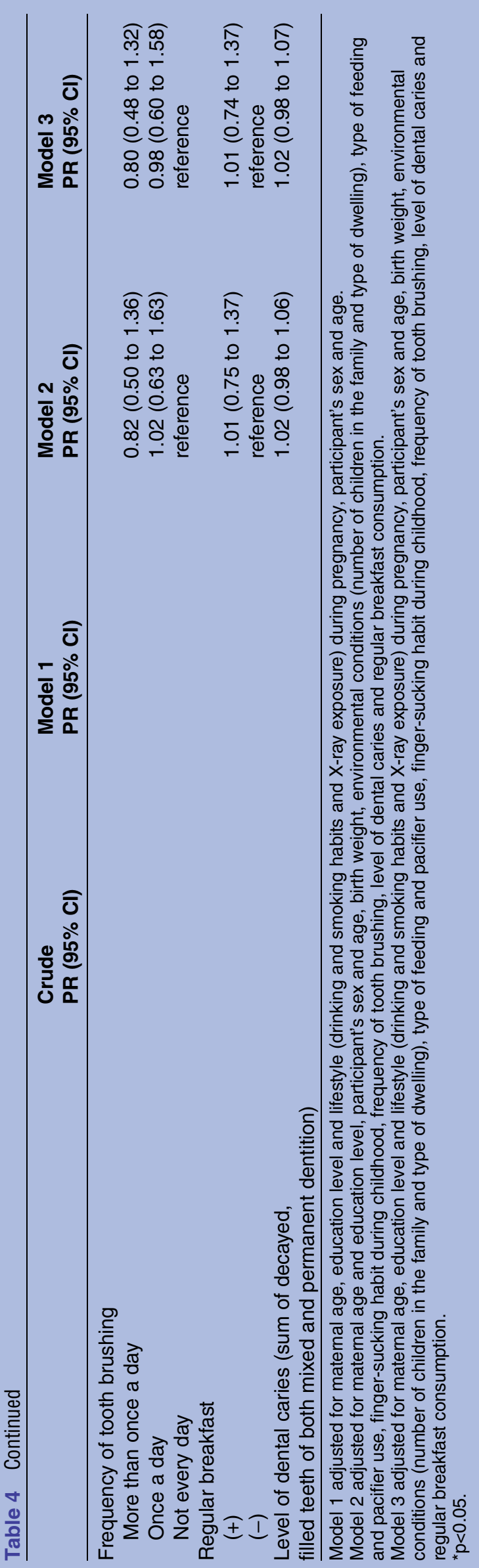

craniofacial growth in children. Further studies are needed about food consumption habits and malocclusion to explain our results.

Mongolians and Japanese people have similar allele frequencies, for instance, for human leucocyte antigen ${ }^{46}$ and leucocyte immunoglobulin-like receptors, ${ }^{47}$ and both belong to the Northeast Asian genetic cluster. However, the prevalence of malocclusion in our sample was $35.2 \%$, which is lower than that in a recent Japanese study in the city of Koshu $(46.5 \%){ }^{8}$ Although formal statistical comparisons were not made and Komazaki et al used a modified IOTN, the Japanese consume a relatively softer diet compared with the Mongolians, which could partially explain this difference.

\section{Limitations}

This study had several limitations. First, only two public schools in the capital city were included. There is therefore a possibility of sampling bias, because maternal educational backgrounds could differ from those of a representative population. However, 88.8\% ( $\mathrm{n}=165$ 908) of the schoolchildren in Ulaanbaatar attend public school. ${ }^{48}$ Second, our study population consisted of adolescents aged 11-16 years, with mixed dentition, which resulted in fair inter-rater agreement for displacement in the lower arch, especially for the erupting lower bicuspids. Using study models but not clinical examination means that indentation on the palate may have been not easily identifiable. Third, excluding individuals with a history of orthodontic treatment could influence the association between maternal educational status and malocclusion. ${ }^{22}{ }^{49}$ However, we excluded any students with an orthodontic treatment history because of the unreliability of grading without information about the state of occlusion prior to orthodontic treatment. The number of students treated with orthodontic appliances was very low $(n=7)$, so we considered that this effect was negligible.

\section{CONCLUSION}

Our study suggests that malocclusion is more prevalent among adolescents with mothers of higher socioeconomic status in Mongolia, with its recent rapid societal changes. Further longitudinal studies following a cohort from early childhood to adolescence are needed to determine the behavioural and environmental circumstances that differ between mothers of high and low educational background in Mongolia, to clarify the reasons for this increased prevalence. Further research is also needed on the association with regional socioeconomic development, to understand how socioeconomic status influences malocclusion and confirm whether this phenomenon is universal or regional.

\section{Author affiliations}

${ }^{1}$ Department of Maxillofacial Orthognathics, Graduate School of Medical and Dental Sciences, Tokyo Medical and Dental University, Tokyo, Japan ${ }^{2}$ Department of Global Health Promotion, Graduate School of Medical and Dental Sciences, Tokyo Medical and Dental University, Tokyo, Japan 
${ }^{3}$ Department of Social Medicine, National Center for Child Health and Development, Tokyo, Japan

${ }^{4}$ Department of Oral Health Promotion, Graduate School of Medical and Dental Sciences, Tokyo Medical and Dental University, Tokyo, Japan ${ }^{5}$ Department of Human Genetics and Disease Diversity, Graduate School of Medical and Dental Sciences, Bioresource Research Center, Tokyo Medical and Dental University, Tokyo, Japan

${ }^{6}$ Department of Molecular Cytogenetics, Medical Research Institute, Bioresource Research Center, Tokyo Medical and Dental University, Tokyo, Japan

${ }^{7}$ Department of Prosthodontics and Orthodontics, School of Dentistry, Mongolian National University of Medical Sciences, Ulaanbaatar, Mongolia ${ }^{8}$ Section of Research and Development, Mongolian National University of Medical Sciences, Ulaanbaatar, Mongolia

Acknowledgements The authors thank all participants and their parents for providing research materials, the administrators of the two schools in Ulaanbaatar for allowing their schools to participate, the teachers and school doctors for distributing questionnaires, the staff of the Department of Maxillofacial Orthognathics of Tokyo Medical and Dental University and the staff and administrators of the Dental Hospital, Department of Prosthodontics and Orthodontics, Department of Pediatric and Preventive Dentistry, School of Dentistry, Mongolian National University of Medical Sciences for their enormous support, without which this project could not have succeeded. They thank their colleagues, Dr Bolormaa Sainbayar and Dr Nomingerel Sukhbaatar, for their tremendous work during data collection. They thank Associate Professor Jun Aida, Department of International and Community Oral Health, Graduate School of Dentistry, Tohoku University for critically revising their manuscript.

Contributors TTu structured the questionnaires, participated in the acquisition of data, performed the IOTN measurement on dental casts and drafted the manuscript. TF contributed to the study design and revised the questionnaires, participated in the acquisition of data, performed the statistical analysis and interpretation of data, and was involved in drafting of the manuscript. YKo helped to structure the questionnaires, participated in the acquisition of data, performed the IOTN, and helped to draft the manuscript. YKa and TTa contributed to the acquisition of data and critically revised the manuscript. JI and $A B$ contributed to the design and revised the manuscript. GG contributed to the acquisition of data and helped in drafting the manuscript. TO contributed to the design, conception and acquisition of data, revised the questionnaires, performed the IOTN, and was involved in drafting of the manuscript. KM contributed to the design, conception and acquisition of data and critically revised the manuscript. All authors read and approved the manuscript.

Funding This work was supported by JSPS KAKENHI grant number 25305037

Competing interests None declared.

Patient consent Obtained.

Ethics approval The Ethical Committees of the Mongolian National University of Medical Sciences (number 13-12/1A) and Tokyo Medical and Dental University (961) approved this study.

Provenance and peer review Not commissioned; externally peer reviewed.

Data sharing statement No additional data are available.

Open Access This is an Open Access article distributed in accordance with the Creative Commons Attribution Non Commercial (CC BY-NC 4.0) license, which permits others to distribute, remix, adapt, build upon this work noncommercially, and license their derivative works on different terms, provided the original work is properly cited and the use is non-commercial. See: http:// creativecommons.org/licenses/by-nc/4.0/

\section{REFERENCES}

1. Proffit WR, Henry W, Fields J, et al. Contemporary orthodontics. 4th edn. Canada: Mosby, Elsevier, 2007:14-16.
2. Evensen JP, Øgaard B. Are malocclusions more prevalent and severe now? A comparative study of medieval skulls from Norway. Am J Orthod Dentofacial Orthop 2007;131:710-16.

3. Jordão LM, Vasconcelos DN, Moreira Rda S, et al. Individual and contextual determinants of malocclusion in 12-year-old schoolchildren in a Brazilian city. Braz Oral Res 2015;29:pii: S1806-83242015000100290.

4. Brook PH, Shaw WC. The development of an index of orthodontic treatment priority. Eur J Orthod 1989;11:309-20.

5. Birkeland K, Boe OE, Wisth PJ. Orthodontic concern among 11-year-old children and their parents compared with orthodontic treatment need assessed by index of orthodontic treatment need Am J Orthod Dentofacial Orthop 1996;110:197-205.

6. Nobile CG, Pavia M, Fortunato L, et al. Prevalence and factors related to malocclusion and orthodontic treatment need in children and adolescents in Italy. Eur J Public Health 2007;17:637-41.

7. Zreaqat $M$, Hassan $R$, Ismail AR, et al. Orthodontic treatment need and demand among 12- and 16 year-old school children in Malaysia. Oral Health Dent Manag 2013;12:217-21.

8. Komazaki Y, Fujiwara T, Ogawa T, et al. Prevalence and gender comparison of malocclusion among Japanese adolescents: a population-based study. J World Fed Orthod 2012;1:e67-72.

9. Nguyen SM, Nguyen MK, Saag M, et al. The need for orthodontic treatment among Vietnamese school children and young adults. Int J Dent 2014:132301.

10. Ngom PI, Diagne F, Dieye F, et al. Orthodontic treatment need and demand in Senegalese school children aged $12-13$ years. An appraisal using IOTN and ICON. Angle Orthod 2007;77: 323-30.

11. Ajayi EO. Normative and self-perceived orthodontic treatment need in Nigerian school children. Acta Odontol Scand 2015;73:364-7.

12. Miguel JA, Feu D, Brêtas RM, et al. Orthodontic treatment needs of Brazilian 12-year-old school children. World J Orthod 2009;10:305-10.

13. Dimberg L, Arnrup K, Bondemark L. The impact of malocclusion on the quality of life among children and adolescents: a systematic review of quantitative studies. Eur J Orthod 2015;37:238-47.

14. von Cramon-Taubadel N. Global human mandibular variation reflects differences in agricultural and hunter-gatherer subsistence strategies. Proc Natl Acad Sci U S A 2011;108:19546-51.

15. Ovsenik M, Farcnik FM, Korpar M, et al. Follow-up study of functional and morphological malocclusion trait changes from 3 to 12 years of age. Eur J Orthod 2007;29:523-9.

16. Proffit WR, Henry W, Fields J, et al. Contemporary orthodontics. 4th edn. Canada: Mosby, Elsevier, 2007:130-61.

17. Ovsenik M. Incorrect orofacial functions until 5 years of age and their association with posterior crossbite. Am J Orthod Dentofacial Orthop 2009;136:375-81.

18. ICOHIRP. Social inequalities in oral health: from evidence to action. Secondary social inequalities in oral health: from evidence to action. 2015. http://www.icohirp.com/monograph.html

19. Proffit WR, Henry W, Fields J, et al. Contemporary orthodontics. 4th edn. Canada: Mosby, Elsevier, 2007:58.

20. Sgan-Cohen HD, Evans RW, Whelton H, et al. IADR Global Oral Health Inequalities Research Agenda (IADR-GOHIRA(R)): a call to action. J Dent Res 2013;92:209-11.

21. Adler NE, Ostrove JM. Socioeconomic status and health: what we know and what we don't. Ann N Y Acad Sci 1999;896:3-15.

22. Tickle M, Kay EJ, Bearn D. Socio-economic status and orthodontic treatment need. Community Dent Oral Epidemiol 1999;27:413-18.

23. Deli $R$, Macri LA, Radico $P$, et al. Orthodontic treatment attitude versus orthodontic treatment need: differences by gender, age, socioeconomical status and geographical context. Community Dent Oral Epidemiol 2012;40(Suppl 1):71-6.

24. Vedovello SA, Ambrosano GM, Pereira AC, et al. Association between malocclusion and the contextual factors of quality of life and socioeconomic status. Am J Orthod Dentofacial Orthop 2016;150:58-63.

25. Robinson $B$, Solongo $A$. The gender dimension of economic transition. In: F Nixson, B Suvd, P Luvsandorj, et al, eds. The Mongolian economy: a manual of applied economics for a country in transition. UK: Edward Elgar Publishing Ltd, 2000:231-55.

26. Manaseki S. Mongolia: a health system in transition. BMJ 1993;307:1609-11.

27. Ganmaa D, Rich-Edwards JW, Frazier LA, et al. A comparison of migrants to, and women born in, urban Mongolia: demographic, reproductive, anthropometric and lifestyle characteristics. Int Health 2013:5:244-50.

28. Dugee O, Khor GL, Lye MS, et al. Association of major dietary patterns with obesity risk among Mongolian men and women. Asia Pac J Clin Nutr 2009;18:433-40. 
29. Jigjid B, Ueno M, Shinada K, et al. Early childhood caries and related risk factors in Mongolian children. Community Dent Health 2009;26:121-8

30. NSO. National report on population and housing situation of Mongolia-2010: full report. Ulaanbaatar: National Statistical Office of Mongolia, 2011:1-274

31. Cooper S, Mandall NA, DiBiase D, et al. The reliability of the Index of Orthodontic Treatment Need over time. J Orthod 2000;27:47-53.

32. Burden DJ, Pine CM, Burnside G. Modified IOTN: an orthodontic treatment need index for use in oral health surveys. Community Dent Oral Epidemiol 2001;29:220-5.

33. Hellman M. An introduction to growth of the human face from infancy to adulthood. Am J Orthod Dentofacial Orthop 1932;18:777-98.

34. Paulsson L, Bondemark L, Soderfeldt B. A systematic review of the consequences of premature birth on palatal morphology, dental occlusion, tooth-crown dimensions, and tooth maturity and eruption. Angle Orthod 2004;74:269-79.

35. Watt RG. Emerging theories into the social determinants of health: implications for oral health promotion. Community Dent Oral Epidemiol 2002;30:241-7.

36. Zhang J, Yu KF. What's the relative risk? A method of correcting the odds ratio in cohort studies of common outcomes. JAMA 1998;280:1690-1.

37. Thomaz EB, Cangussu MC, Assis AM, et al. Malocclusion and deleterious oral habits among adolescents in a developing area in northeastern Brazil. Braz Oral Res 2013;27:62-9.

38. Normando TS, Barroso RF, Normando D. Influence of the socioeconomic status on the prevalence of malocclusion in the primary dentition. Dental Press J Orthod 2015;20:74-8.
39. Dinsa GD, Goryakin Y, Fumagalli E, et al. Obesity and socioeconomic status in developing countries: a systematic review. Obes Rev 2012;13:1067-79.

40. NSO. Child and development (MICS-3), final report. Ulaanbaatar: National Statistical Office of Mongolia, 2007.

41. Viinanen A, Munhbayarlah S, Zevgee T, et al. The protective effect of rural living against atopy in Mongolia. Allergy 2007;62:272-80.

42. Frazão P, Narvai PC. Socio-environmental factors associated with dental occlusion in adolescents. Am J Orthod Dentofacial Orthop 2006;129:809-16.

43. Zhang J, Guo Z, Lim AA, et al. Mongolians core gut microbiota and its correlation with seasonal dietary changes. Sci Rep 2014;4:5001.

44. Varrela J. Masticatory function and malocclusion: a clinical perspective. Semin Orthod 2006;12:102-9.

45. WHO. Mongolian STEPS Survey on the Prevalence of Noncommunicable Disease and Injury Risk Factors 2009. Geneva: World Health Organization, 2010.

46. Chimge NO, Tanaka H, Kashiwase $\mathrm{K}$, et al. The HLA system in the population of Mongolia. Tissue Antigens 1997:49:477-83.

47. Hirayasu $\mathrm{K}$, Ohashi J, Tanaka $\mathrm{H}$, et al. Evidence for natura selection on leukocyte immunoglobulin-like receptors for HLA class I in Northeast Asians. Am J Hum Genet 2008;82:1075-83.

48. MECS. Statistic report of primary and secondary education 2012-2013 Academic Year. Ulaanbaatar: Ministry of Education, Culture and Science, Mongolia, 2013.

49. Krey KF, Hirsch C. Frequency of orthodontic treatment in German children and adolescents: influence of age, gender, and socio-economic status. Eur J Orthod 2012;34:152-7. 